\title{
De la Generación del 80 a la década del 30. La literatura como memoria de clase
}

\author{
Rubén Dellarciprete \\ Centro de Literaturas y Literaturas Comparadas \\ IdIHCS (Instituto de Investigaciones en Humanidades \\ y Ciencias Sociales), Facultad de Humanidades y Ciencias \\ de la Educación, Universidad Nacional de La Plata \\ rdell@netverk.com.ar / rdellarciprete13@gmail.com
}

\section{Resumen}

Observar, decodificar, categorizar y contar son todas operaciones dirigidas contra la evanescencia de la modernidad. La venganza, la atrofia estética, el arribismo, la indecencia, la frivolidad liberal constituyen estigmas indeseables que atentan contra la «integridad» de Lucio V. López y sus representados. El autor de La gran aldea (1884) ve peligrar los intereses económicos y culturales, y construye una «memoria literaria» que intenta clausurar por derecha e izquierda la simbólica Buenos Aires. Al igual que Enrique Loncán en Aldea Millonaria (1933), mira sin comprender lo que Wilde había definido con simplicidad filosófica: «La conservación absoluta es una imposibilidad en el mundo en que todo va de tránsito». Las nuevas comunidades locales, que constituían la densa amalgama demográfica y social, y su modo de habitar Buenos Aires, se van apropiando del imaginario y sus variables simbólicas para modificar progresivamente la memoria constituida sobre las identidades tradicionales.
Palabras clave:

tradición, memoria, elitismo, modernidad, Buenos Aires. 


\section{Abstract}

To observe, decodify, categorize and relate, are all operations against modernity evanescence. Revenge, aesthetic atrophy, indecency and liberal frivolity are the undesiKey words: tradition, memory, literature, modernity, Buenos Aires. rable stigmas which attempt against Lucio V. López «integrity» and his group. In La gran aldea (I884) the author believes that economic and cultural interests are in danger and makes «literary memory» trying to close by all means the symbolic Buenos Aires. As Enrique Loncán in Aldea Millonaria (1933) sees without understanding what Eduardo Wilde had defined with filosofic simplicity: «Absolute conservatio is an imposibility in this world where everything changes.» The new local communities, which will conform the dense demographic and social amalgam and their way to occupy Buenos Aires, are appropriating the imaginary ideas and their symbolic variables in order to modify progressively the constituted memory about traditional indentities.

\section{Un intérprete de la historia reciente} Literatura de observación y crítica El viaje al pasado de Lucio V. López en La gran aldea se fundamenta en diversidad de motivos, preservar la memoria colectiva, construir un sujeto competente que pueda dar cuenta de esa memoria, o exteriorizar preocupaciones de índole personal, como sugiere David Viñas en Literatura Argentina y politica:

A través del empastado y sublimación novelescas, Lucio V. López, se desquita de la humillación sufrida por su padre Vicente Fidel López, durante las jornadas de junio de I852 en las que defendió el pacto de San Nicolás y fue vencido por Mitre y la política porteña. La gran aldea se aparece como literatura de venganza. (Viñas, 2005:7I)

No tan sólo literatura de venganza, probablemente se trate de literatura de observación y crítica. El cronista Julio Rolaz, narrador de la novela, es un intérprete de la historia reciente. Durante la primera parte de la estructura narrativa regresa al pasado, ejerce la memoria, para saldar cuentas con el mitrismo; en la segunda observa y elabora el relato sobre «el disgusto nacional», combina- 